Esta revista forma parte del acervo de la Biblioteca Jurídica Virtual del Instituto de Investigaciones Jurídicas de la UNAM

\title{
La dudosa validez de la elección presidencial 2012
}

\section{Jaime Cárdenas}

\section{Sumario:}

I. El lugar común

II. Las características del proceso electoral

III. El juicio de inconformidad 359/2012

IV. La resolución de la Sala Superior del Tribunal Electoral del Poder Judicial de la Federación. Descripción y crítica

V. Conclusiones. La reforma electoral que viene

* Doctor en Derecho por la UNAM, y por la Universidad Complutense de Madrid. Tiene especialidad en Derechos Humanos y Ciencias Políticas. Ha sido Visiting Fellow en la Universidad de Yale y Visiting Researcher en la Universidad de Georgetown. Es investigador del CONACYT, nivel III e investigador en el Instituto de Investigaciones Jurídicas de la UNAM. Ha escrito y publicado diversos libros en las materias de su especialidad. Ha sido consejero electoral del Consejo General del IFE; consejero de la judicatura del Distrito Federal, y diputado federal.

D. R. () 2013. Universidad Nacional Autónoma de México-Instituto de Investigaciones Jurídicas. 


\section{El lugar común}

Es ya casi un lugar común señalar que el fin de la transición democrática en México y la consolidación democrática nacional requieren reformas que vayan más allá de lo electoral. ${ }^{1}$ Lo anterior quedó evidenciado en el proceso electoral de 2012, pues aunque se tenga un sistema electoral más o menos aceptable, si los poderes fácticos lo controlan, si influyen en él a través del empleo ilegal del dinero, o si los medios de comunicación electrónica del país que concentran más del 90\% del espectro radioeléctrico promueven una candidatura en detrimento de las otras, el sistema electoral formalmente adecuado sucumbirá o será cuando menos afectado por factores en principio externos a él.

Los que piensan como Schumpeter que la democracia es un mero mecanismo para la selección de élites o como Popper que sostiene que es un procedimiento de destitución de gobernantes, insistirán que la transición a la democracia en México ha concluido. La democracia en esta concepción formal y minimalista se concreta y concluye en lo electoral sin que importe mucho la calidad de las reglas e instituciones. Se trata de una mistificación que paraliza el sentido de la democracia en el tiempo. ${ }^{2}$ La democracia pone fin a la historia si es sólo una cuestión de reglas y procedimientos para saber quién gobierna y cómo gobernará.

Las visiones minimalistas de la democracia centradas en lo electoral, además de incorrectas son falsas, pues como sabemos muchos mexicanos, a lo electoral le falta un buen trecho por recorrer y, aunque redujéramos la democracia a lo electoral, tendríamos que concluir que ese ámbito permanece inconcluso e inacabado. Los principios de elecciones libres, auténticas y periódicas no han quedado agotados, ni por la vía de la reforma legislativa, y menos por la vía de la interpretación judicial.

La democracia no implica sólo la existencia de elecciones y partidos competitivos, seguramente por ahí se empieza, pero eso no basta para

1 Cárdenas Gracia, Jaime, Transición política y reforma constitucional en México, México, UNAM, 1994.

2 De Vega, Pedro, "La democracia como proceso (Algunas consideraciones desde el presente del republicanismo de Maquiavelo)”, en Guerra, Alfonso, y Tezanos, José Félix (eds.), Alternativas para el siglo XXI. I Encuentro Salamanca, Madrid, Sistema, 2003, p. 465 . 
hablar de democracia. La posición minimalista de Schumpeter como lo ha demostrado Larry Diamond ${ }^{3}$ conlleva a la falacia electoralista, pues no por contar con elecciones se califica a un país de democrático, es necesario ver cómo se garantizan las libertades y las modalidades de expresión de la sociedad civil; en otras palabras, los requerimientos institucionales de la democracia como el "rule of law", la división de poderes, la rendición de cuentas y, en general, las condiciones o elementos institucionales del ejercicio del poder forman parte integrante del concepto de democracia. Las reglas e instituciones electorales, por sí mismas, sin otros arreglos institucionales que promuevan los derechos humanos o el Estado de derecho hacen imposible que hablemos de una democracia. ${ }^{4}$

En estas condiciones, sostener que México ha llegado al fin de su transición democrática porque a nivel federal — no siempre a nivel de los estados - tenemos un sistema electoral más o menos avanzado aunque no equitativo ni participativo, entraña reducir el concepto democrático al no entender que la democracia no es capaz de pervivir sin un Estado constitucional de derecho y sin la garantía efectiva de los derechos fundamentales, elementos que se deben concebir dentro de un proceso evolutivo.

En otro trabajo propuse diversas reformas institucionales para lograr el diseño de un nuevo Estado constitucional y democrático de derecho, para contar con una democracia consolidada, ${ }^{5}$ las que resumí en diez puntos que aquí solamente enuncio: 1) limitación y sujeción a derecho de los poderes fácticos; 2) un nuevo entendimiento sobre los derechos fundamentales que integre un catálogo amplio de derechos que cuente con garantías plenas de realización; 3) la democratización, transparencia, rendición de cuentas, eficiencia y eficacia de todas las instituciones del Estado; 4) la garantía plena de la supremacía constitucional y de los tratados internacionales; 5) mecanismos de cumplimiento efectivo de los principios constitucionales mediante un nuevo

3 Diamond, Larry, Developing, Democracy Toward Consolidation, Baltimore, The Johns Hopkins University Press, 1999.

4 Przeworski, Adam, "Minimalist Conception of Democracy: a Defense", en Shapiro Ian, y Hacker-Cordón, Casiano, Democracy's Value, Cambridge, Cambridge University Press, 1999, pp. 23-55.

5 Cárdenas Gracia, Jaime, "La construcción del Estado constitucional en México”, en Molina Piñeiro, Luis et al., ¿Constitucionalizar democratiza?, México, Porrúa-UNAM, 2011, pp. 82-105. 
derecho procesal constitucional pensado para dotar a los ciudadanos de legitimidad procesal; 6) establecimiento de mecanismos anticorrupción que no permitan la impunidad que prevalece en el país y sancionen a las autoridades y particulares que participan en conductas corruptas; 7) inclusión en los tres niveles de gobierno del mayor número de medios de democracia participativa y deliberativa; 8) recuperación del patrimonio de la nación - sus recursos naturales- y de su explotación por el Estado; 9) defensa de la soberanía nacional, y 10) cambios al modelo económico neoliberal para poner la economía al servicio de las mayorías.

\section{Las características del proceso electoral}

Algunas de las características que prevalecieron en este proceso electoral fueron: exceso en el gasto electoral; judicialización de sus etapas; uso de los programas públicos y del presupuesto para apoyar a los futuros candidatos; compra y coacción del voto; propaganda política encubierta con el apoyo de los grandes medios de comunicación electrónica y uso de las encuestas con fines de propaganda electoral; esquemas de financiamiento paralelo e ilícito; la presencia visible e invisible del crimen organizado, y la aparición de un movimiento social juvenil que ha rechazado el proceso electoral y sus resultados, principalmente por el papel indebido que los medios de comunicación electrónica han jugado en él y en la vida pública del país (el movimiento estudiantil \#YoSoy132).

El exceso de gasto en las campañas se expresó desde las primeras semanas de la campaña electoral. Así, el 26 de abril de 2012 los representantes de los tres partidos de la coalición Movimiento Progresista presentaron una queja por violación al tope de gastos de campaña por parte del candidato priista y solicitaron "medidas cautelares para hacer cesar la conducta denunciada, a fin de preservar el principio de equidad y garantizar la validez de la elección". Se entregaron pruebas que sustentaban la estimación de que al 24 de abril de 2012 el candidato del PRI, había realizado un gasto de campaña que ascendía ya a la cantidad de $\$ 374920338.21$, tan solo en rubros de gastos como anuncios de bardas y espectaculares, así como en la realización de actos, con lo que rebasaba lo permitido en \$38 808 254.05. 
El 5 de junio de 2012, la coalición Movimiento Progresista presentó una ampliación a la queja en contra del PRI por violación al tope de gastos, solicitando medidas cautelares, pues se evidenció que al 2 de junio, el candidato Enrique Peña Nieto ya había gastado $\$ 719500989.00$ tan solo en propaganda y actos de campaña cuantificables, rebasando el tope en \$383 388905.17 . Es decir, más del doble de lo legalmente permitido. $^{6}$

Posteriormente, el 10 de julio de 2012, los partidos de la coalición de izquierda presentaron una segunda ampliación de queja por rebase de gastos por parte del PRI. Según las estimaciones de esa coalición el gasto de campaña de Peña Nieto para el periodo del 3 al 27 de junio de 2012 era entonces de $\$ 1173486884.00$. Esto es, entre la primera queja interpuesta el 26 de abril del 2012 y la del 10 de julio del mismo año, la coalición PRI-PVEM — según la coalición Movimiento Progresista - había gastado únicamente para campaña presidencial, y "tan sólo en propaganda y actos de campaña cuantificables", la cantidad de $\$ 1892987873.00$. Por último, el 12 de julio de 2012, en el juicio de inconformidad 359/2012, se sostuvo que la coalición Compromiso por México había erogado en la campaña la cantidad de $\$ 459947834.00$, que era lo que hasta entonces se había podido acreditar por la coalición de izquierda. ${ }^{7}$

La judicialización del proceso electoral fue una de las características permanentes del proceso electoral federal de 2012. Bastaba seguir la prensa de esos meses para advertir cómo los partidos y coaliciones presentan permanentemente quejas e impugnaciones ante la autoridad electoral federal que después de resueltas —en los casos en que así ocurría - eran impugnadas ante las diversas salas del Tribunal Electoral del Poder Judicial de la Federación. Cualquier estrategia electoral era inmediatamente contestada por la fuerza política adversaria a través de una denuncia o por medio de una impugnación. Esas conductas deberían ser encomiables si hubiesen estado guiadas para salvaguardar el acceso a la justicia, la legalidad y equidad del proceso. Sin embargo, la judicialización del proceso electoral federal de 2012

6 El tope de gastos de la campaña presidencial en 2012 fue de \$336112084.16 (trescientos treinta y seis millones ciento doce mil ochenta y cuatro pesos 16/100 M.N.)

7 Consúltese el Juicio de Inconformidad de la Coalición Movimiento Progresista presentado el 12 de julio de 2012 ante las autoridades electorales (JIN 359/2012), pp. 226 y ss. 
tuvo que ver poco con la garantía de la legalidad electoral y mucho con la estrategia general de comunicación de cada partido o coalición.

Una tercera característica del proceso entrañó el uso ilegal de los recursos presupuestales federales, estatales y municipales para apuntalar a los distintos candidatos. El gobierno federal destinó ese año millones de pesos de los programas sociales con fines claramente clientelares y de manipulación social. Los gobiernos estatales y municipales hicieron lo propio. ¿Cómo evitar esta simulación? La fiscalización de los recursos públicos en México es del todo precaria. La Auditoría Superior de la Federación, por ejemplo, ejerce ese control muy limitadamente cuando el proceso electoral ya ha concluido. En cuanto a las autoridades electorales, éstas concluyen la revisión de los informes de gastos de campaña y resuelven las quejas en materia de fiscalización cuando el proceso electoral ya ha sido validado.

En la prensa escrita del país se informó que el 12 de junio de 2012, en Toluca, Estado de México, en la casa oficial del gobernador del Estado de México, 16 gobernadores del PRI se reunieron con el candidato presidencial Peña Nieto y su equipo de campaña. ${ }^{8}$ Se adujo que en esa reunión se establecieron "cuotas" de votos que cada gobernador tenía que obtener, aunque los coordinadores de la campaña de Peña Nieto lo negaron. Por ejemplo, se dijo que Eruviel Ávila, gobernador del Estado de México, se comprometió a conseguir 2900000 votos. Estos hechos implicarían el empleo de recursos públicos a través de programas sociales o por otras vías para lograr ese objetivo político de carácter ilícito.

El 2 de agosto de 2012, Ricardo Monreal Ávila, coordinador de campaña de la coalición Movimiento Progresista, dio a conocer la existencia de la cuenta 806935 de Scotiabank, que pertenece al gobierno del Estado de México, pero que aparentemente administraba el coordinador de la campaña de Enrique Peña Nieto, Luis Videgaray Caso. Esta cuenta administró en inversiones, de febrero a junio de 2012, alrededor de ocho mil millones de pesos, quedando otra vez con un saldo menor, a finales de junio de 2012. Aun cuando los dirigentes del PRI, el banco y el gobierno del Estado de México, respondieron que se trataba de un infundio, los hechos han ameritado investigaciones que se encuentran en curso ante diversas instancias del país.

$8 \quad$ La Jornada, 13 de junio de 2012. 
La compra y coacción del voto hizo acto de presencia en el proceso electoral de 2012. Pedir el sufragio a cambio de bienes es toda una tradición en nuestro país, en donde la clase política lucra electoralmente con la pobreza y la desigualdad. Seguramente una de las caras más reprensibles de la vida política y formalmente democrática de México tiene que ver con estas prácticas que nos avergüenzan a todos pero que hemos sido incapaces de evitar, verbigracia, a través de una reforma electoral preventiva y de otra penal que considere que cualquier conducta que signifique compra o coacción del voto constituye un delito similar a los que conforman el catálogo de delitos de delincuencia organizada.

La compra del voto se dio prácticamente en todo el país pero fue más acentuada en las zonas rurales y marginadas de carácter urbano. En estos lugares se registró el mayor nivel de participación ciudadana del país, contrario a lo sucedido en las anteriores elecciones presidenciales y por encima de la media nacional registrada en los actuales comicios. Por ejemplo, en los tres distritos con más población rural de Yucatán, se registró una participación promedio del 86\%. En Chiapas, la participación ciudadana, con respecto a 2006, se incrementó en $118 \%$. En el medio urbano, con relación a 2006, la participación creció en $5.16 \%$, mientras en el medio rural aumentó en $23.37 \%$.

Para la obtención de los votos, los candidatos entregaron dinero en efectivo, comida, materiales de construcción y otras dádivas, aprovechando la pobreza extrema de millones de mexicanos que carecen hasta de lo indispensable. Solamente la coalición Compromiso por México - PRI-PVEM - entregó cerca de trescientos utilitarios diversos, desde licuadoras y estufas eléctricas hasta camisetas y cosméticos para mujer.

La prueba de que esta elección presidencial fue definida por el uso del dinero para la compra de votos es que, en las ciudades, las tendencias electorales fueron distintas a las del medio rural, y no sólo porque en las primeras hay más información, sino también porque en ellas, los partidos no aplicaron la estrategia de comprar votos a integrantes de las clases medias. En las casillas urbanas, que son el $65 \%$ del total, según cifras oficiales, Peña Nieto superó a Andrés Manuel López Obrador con 528383 votos. Los otros casi tres millones de votos de ventaja los obtuvo el candidato de la coalición Compromiso por México en el medio rural. 
En las 902 casillas especiales instaladas en todo el país, en las que los ciudadanos sufragaron libremente, el resultado fue completamente distinto: por Josefina Vázquez Mota votó el 27.8\%; por Enrique Peña Nieto 28.1\%; por López Obrador 41.0\%; por Gabriel Quadri 1.6\%; candidatos no registrados $0.2 \%$; y votos nulos $1.2 \%$. En este tipo de casillas, el candidato de la coalición Compromiso por México sólo gana en 4 estados de las 32 entidades de la República.

Organizaciones No Gubernamentales de observación electoral como Alianza Cívica, en el informe que remitieron a las autoridades electorales concluyeron que el $28.4 \%$ de los sufragios fue comprado, que en el $21 \%$ de las casillas que vigiló esa organización existieron reportes de violación al voto secreto, y que el 18\% de los ciudadanos por ellos encuestados expresaron que fueron presionados para votar. ${ }^{9}$ Agregaron en su informe que existe una correlación entre el dinero de las campañas y los resultados electorales.

La propaganda encubierta vía los medios de comunicación electrónica fue harto significativa. En 2006 se emplearon las campañas negras. Hoy en día están desacreditadas constitucionalmente porque se prohíbe la compra y/o adquisición de tiempos en radio y televisión. El monitoreo elaborado por la UNAM a solicitud del IFE señala que el candidato del PRI-PVEM ocupó el mayor tiempo destinado por los noticiarios de radio y televisión, y aun cuando no se calificaron notas informativas correspondientes a los géneros de opinión, análisis y debate, de 3853 valoraciones de los cuatro candidatos, Peña Nieto tuvo 668 menciones positivas y 480 negativas, mientras López Obrador recibió 477 valoraciones positivas y 974 negativas.

Empresas como GEA-ISA/Milenio, El Universal/Buendía y Laredo, BGC/Excélsior, Consulta Mitofsky/Radio Fórmula/Televisa, entre otras, se dedicaron a difundir resultados día a día que no correspondieron con los resultados oficiales finales y cuyo propósito fue proyectar la imagen de que el candidato del PRI-PVEM era inalcanzable. Por ejemplo, la encuesta GEA-ISA/Milenio se difundió diariamente en periódicos, radio y televisión, durante toda la campaña. El 27 de junio, último día de campaña, el diario Milenio, en titulares, sostuvo que "tras 101 días de seguimiento diario electoral" Peña Nieto mantiene una ventaja de $18.4 \%$, casi tres veces superior al resultado oficial.

9 Boletín de prensa de Alianza Cívica, A. C., de 3 de julio de 2012. 
La manipulación de los medios de comunicación electrónica se tradujo, según nuestro punto de vista, en propaganda disfrazada, promovida por los dueños de empresas de medios de información para eludir la prohibición expresa a los particulares de contratar tiempos en radio y televisión. Es decir, se violaron los párrafos 2 y 3 del inciso $g$, de la base III, del artículo 41 de la Constitución, los artículos 49.3 y 49.4 del Código Federal de Instituciones y Procedimientos Electorales, así como el "Acuerdo del Consejo General del Instituto Federal Electoral que estableció los lineamientos y los criterios de carácter científico que deberán observar las personas físicas y morales que pretendan ordenar, realizar y/o publicar encuestas por muestreo, encuestas de salida y/o conteos rápidos durante el proceso electoral 2011-2012".

El 26 de junio de 2012 el Partido Acción Nacional presentó una denuncia ante el IFE y la FEPADE, entregando como pruebas dos tarjetas Monex Recompensa, con sus respectivos testimonios notariales, de dos ciudadanos de Guanajuato que aseguraron haber recibido estos monederos electrónicos como pago por su desempeño en la estructura electoral del PRI. En su escrito, el PAN demandó la investigación correspondiente, asegurando que el PRI había destinado 700 millones de pesos para este propósito.

Después, la coalición Movimiento Progresista recibió 33 facturas y una relación de depósitos para la adquisición de tarjetas Monex por un monto de 108200764 pesos. En dichas facturas aparecen como clientes el Grupo Comercial Inizzio, S.A. de C.V., y la Importadora y Comercializadora Efra, S.A. de C.V., los cuales compraron a Monex 10674 tarjetas, con sus respectivas cargas de "saldos prepago". Tres días después, el 15 de julio de 2012, en entrevista con el periódico Reforma, el director de Monex, admitió tácitamente la autenticidad de las facturas.

El 19 de julio de 2012 el PRI aseguró que había contratado a la empresa Alkino Servicios y Calidad, S.A. de C.V. para manejar 7850 tarjetas, por un monto total de 66326300 pesos y que estos recursos sólo se habían distribuido el día de la elección para pagar a quienes participaron como integrantes de su estructura electoral.

A partir del 13 de julio de 2012, la coalición Movimiento Progresista recibió tarjetas denominadas Monex-Lealtad, Monex Recompensa, y Broxel Monex Lealtad Internacional. La mencionada coalición entregó a las autoridades electorales federales una relación de 4891 personas que recibieron tarjetas del Banco Monex. Según la coalición, 
las personas beneficiadas no necesariamente actuaban como representantes de casilla, sino como promotores del voto a favor de Enrique Peña Nieto. Según la coalición Movimiento Progresista debieron ser utilizadas alrededor de 260000 tarjetas en todo el país. Un promedio de 4 por sección, lo que llevaría a sostener que sólo por este concepto la coalición "Compromiso por México", a través de múltiples empresas fantasmas, contrató más de mil millones de pesos con el Banco Monex. ${ }^{10}$

El PRI trató de desacreditar la campaña de López Obrador cuando ésta estaba en curso, principalmente a través del escándalo que los medios de comunicación electrónica denominaron "el Charolagate". ${ }^{11}$ Con ese nombre ha sido llamada por los adversarios de Andrés Manuel López Obrador la difusión de una cena que se supone fue inmoral y que tuvo tintes ilícitos. En ese encuentro privado realizado el 24 de mayo de 2012 en la casa del licenciado Luis Creel, se reunieron un grupo de empresarios con Luis Mandoki y Adolfo Hellmund, colaboradores del candidato presidencial de la coalición Movimiento Progresista. Según la información vertida también asistió a ese encuentro Luis Costa Bonino, estratega de campañas presidenciales en distintos países del mundo.

La acusación lanzada desde el PRI y con menor intensidad por el PAN, consiste en señalar que en esa cena, los colaboradores de López Obrador solicitaron seis millones de dólares a los empresarios ahí reunidos para la campaña y, que esa petición violentaba, en contravención a la ley electoral federal, los topes de aportación individual y de campaña previstos en ella.

Desde la perspectiva jurídica, si no existe la aportación o transferencia no se configura ninguna violación al Cofipe. Para que exista violación a la ley electoral federal se requiere la materialización, la entrega efectiva de los recursos. Si los seis millones de dólares se hubiesen entregado a los colaboradores y se hubieren destinado a la campaña de López Obrador sí se cumplirían los extremos de la violación legal. Al

\footnotetext{
10 Véase el expediente del Juicio de Inconformidad 359/2012.

11 Hubo otros escándalos en contra de López Obrador que el PRI impulsó sin éxito como los relacionados con las asociaciones civiles "Honestidad Valiente, A.C", "Austeridad Republicana" y "Morena, A.C.". En opinión del PRI estas personas morales habrían otorgado recursos a la campaña de López Obrador. Sin embargo, algunas de ellas como Morena no cuentan, según la Unidad de Fiscalización del IFE por información que ha trascendido en los medios de comunicación, con cuentas bancarias ni chequeras.
} 
no haberse entregado de los recursos no existe infracción. Penalmente, las conductas del "Charolagate" tampoco implican la comisión de un delito. Lo ocurrido en la cena no actualiza ninguna de las hipótesis contempladas en el título vigésimo cuarto del Código Penal Federal en materia de delitos electorales. Es difícil también que se trate de una extorsión o de un delito cometido por servidores públicos porque los colaboradores de López Obrador no eran funcionarios públicos $y$, porque hasta donde se desprende de las grabaciones de la cena, no obligaron a los empresarios a entregar recurso alguno.

En cuanto al crimen organizado, aun no sabemos el papel que efectivamente tuvo en este proceso electoral. Sin embargo, conocemos que la autoridad electoral federal tuvo problemas, en las zonas del país en donde es fuerte la presencia del narcotráfico, a la hora de capacitar ciudadanos para que fungieran como funcionarios electorales en las mesas de casilla. En cuanto a las fuentes del financiamiento, aún ignoramos si hubo recursos en las precampañas y campañas provenientes del crimen organizado.

La gran novedad en el proceso electoral de 2012 fue la aparición del movimiento universitario "\#YoSoy132". El viernes 11 de mayo de 2012, como parte de su campaña electoral, Peña Nieto visitó la Universidad Iberoamericana. En el encuentro con los jóvenes estudiantes Peña fue cuestionado por los actos de represión que ordenó cuando fue gobernador del Estado de México - San Salvador Atenco- y por sus vínculos con la empresa Televisa. Los estudiantes de la Universidad Iberoamericana primero y después los estudiantes de diversas universidades del país, han denunciado el contrato secreto entre Peña Nieto y Televisa y el papel corruptor de la televisión mexicana en la vida pública del país. El movimiento social \#YoSoy132 ha rechazado los resultados electorales y lo que se considera la imposición de Peña Nieto como presidente de México. Como dice Pipitone, los estudiantes de ese movimiento han entendido que la televisión mexicana, principal fuente de información popular, es un lastre que traba el progreso civil del país y que se añade a criminalidad en ascenso, instituciones ineficaces-corruptas y poco empleo. ${ }^{12}$

Las redes sociales tuvieron gran trascendencia en este proceso electoral federal y han sido el principal instrumento de comunicación

12 Pipitone, Ugo, “El regreso del PRI”, Revista Claves de Razón Práctica, Madrid, septiembre-octubre de 2012, núm. 224, p. 90. 
política y de crítica del movimiento \#YoSoy132. Es un hecho que las redes sociales tendrán una influencia decisiva en próximos procesos electorales. En ellas se comunican alrededor de cuarenta millones de mexicanos y en 2012 tenían posibilidad de votar cerca de 14 millones de jóvenes, que son los que utilizan con mayor asiduidad este instrumento. Se dice que en México y en el uso de las redes sociales no hemos llegado al empleo que tienen en los Estados Unidos, los países de Europa Occidental o el Japón, lo que desde luego es cierto, pero no por ello debemos minimizar su importancia e influencia en la discusión y deliberación política de nuestro país.

En México más de cincuenta millones de mexicanos viven en la pobreza y, muchos de esos ciudadanos antes de conectarse en la red demandan estar alimentados y tener condiciones de vida aceptables. Sin poner en duda la anterior, algunos de los jóvenes mexicanos que viven en condiciones sociales deplorables, desean, sin embargo, conectarse a la red, como lo hacen el resto de los jóvenes. La televisión en cambio pierde influencia entre millones de jóvenes. La televisión sigue teniendo influencia en las personas de mediana edad o en los adultos mayores. Se estima que el noticiero más visto de la empresa "Televisa" es observado diariamente por nueve millones de personas, lo que significa que aunque aún es un medio poderoso para la penetración política, va perdiendo capacidad de acceso entre los mexicanos.

En las elecciones de 2012, la televisión y la radio en nuestro país, jugaron aún un papel importante, pero estimo que para el proceso electoral presidencial de 2018 no tendrán una trascendencia fundamental. Esta conjetura nos obliga a preguntarnos sobre las medidas que ha adoptado la autoridad electoral ante el auge e importancia creciente de las redes sociales en el proceso electoral. La respuesta es casi nada. En buena parte porque las redes sociales y por fortuna, hasta el momento, constituyen un espacio de libertad y de deliberación pública horizontal, y porque la legislación electoral no confiere muchas herramientas jurídicas para intervenir, con la excepción muy relativa de las expresiones que en la red denigren a las instituciones o calumnien a las personas.

La televisión y la radio en este proceso electoral influyeron indebidamente como lo hicieron en 2006 durante el proceso electoral. La vía principal - aunque no la única- que ejercieron para intervenir, consistió en el uso de encuestas. Este camino les permitió beneficiar a Peña Nieto y presentarlo como el candidato presidencial que iba 
con una delantera en las preferencias, imposible de empatar y mucho menos alcanzar. A partir de su información argumentaron sobre la inevitabilidad de los futuros resultados electorales. Ese expediente constituyó en los hechos, no la presentación de la información de las encuestas en sí, sino una suerte de manipulación hacia los ciudadanos generadora de inequidad electoral además de la comisión de diversas violaciones constitucionales y legales a las normas electorales que prohíben la compra y/o adquisición de tiempos en radio y televisión.

Por eso, las redes sociales pueden constituir en el futuro político-electoral del país un antídoto frente a las actitudes de la televisión o la radio. En las redes sociales se pueden organizar encuestas y sondeos alternativos, al margen de las televisoras, y como son un espacio de comunicación y deliberación horizontal entre los ciudadanos, se contrastarán los resultados de las encuestas de la red con los resultados de las encuestas de las televisoras y, seguramente estarán en aptitud de cuestionar a las encuestas de la televisión, tanto en su metodología como en su veracidad o, en su uso social manipulativo.

Las anteriores son a nuestro juicio algunas características del proceso electoral de 2012, pero evidentemente no son las únicas. Estos rasgos muestran que los procesos electorales federales del país aún no se desarrollan en condiciones de libertad y autenticidad. También nos enseñan que el sistema electoral es sólo una vertiente del sistema político en su conjunto y que mientras este sistema no sea modificado integralmente, los procesos electorales naufragarán en la inconstitucionalidad e ilegalidad, pues seguirán siendo materia de polémica nacional y de descrédito para las instituciones electorales del país.

Sin embargo, para las autoridades electorales, tanto Instituto Federal Electoral como Tribunal Electoral del Poder Judicial de la Federación, se cumplieron a cabalidad las etapas del proceso electoral y se realizaron los actos de cada una de ellas en los términos previstos en la Constitución y en las leyes electorales. Consideraron que en el proceso electoral federal de 2011-2012 prevalecieron los principios y valores constitucionales en materia electoral como son los derechos fundamentales a ser votado; el de acceso de los ciudadanos en condiciones de igualdad a las funciones públicas del país; el de elecciones libres, auténticas y periódicas; de sufragio universal, libre, secreto y directo; de maximización de la libertad de expresión, y del derecho de información en el debate público que precede a las elecciones. 
De acuerdo con el cómputo final de la elección de presidente de los Estados Unidos Mexicanos y la declaratoria de validez correspondiente emitida en los términos del artículo 99 de la Constitución por la Sala Superior del Tribunal Electoral del Poder Judicial de la Federación, Peña Nieto obtuvo diecinueve millones ciento cincuenta y ocho mil quinientos noventa y dos votos de un universo de cincuenta millones ciento cuarenta y tres mil seiscientos dieciséis sufragios emitidos. El candidato de la coalición Movimiento Progresista obtuvo quince millones ochocientos cuarenta y ocho mil ochocientos veintisiete votos. La candidata del Partido Acción Nacional recibió doce millones setecientos treinta y dos mil seiscientos treinta votos. El candidato de Nueva Alianza fue apoyado por un millón ciento cuarenta y seis mil ochenta y cinco votos. Los votos nulos fueron más de un millón doscientos treinta y seis mil votos. ${ }^{13}$

\section{El juicio de inconformidad 359/2012}

Una vez que el secretario ejecutivo del Consejo General informó al Consejo General del IFE con fundamento en el artículo 310 del Cofipe del resultado de la sumatoria de los resultados consignadas en las actas de cómputo distrital de la elección para presidente, en el plazo de ley, la coalición Movimiento Progresista el 12 de julio de 2012 impugnó la elección de presidente de los Estados Unidos Mexicanos por nulidad de toda la elección, y solicitó a la Sala Superior del Tribunal Electoral del Poder Judicial de la Federación, la declaración de no validez de la elección presidencial por violación a los principios constitucionales de elecciones auténticas y sufragio libre. Además, promovió la cancelación de registro de candidato al ciudadano Enrique Peña Nieto por rebasar los topes de gastos de campaña.

En el juicio de inconformidad 359/2012, se sostuvo que en un Estado de derecho las elecciones no pueden darse o realizarse de cualquier forma y no pueden consistir en una simulación. En un Estado de dere-

13 Dictamen sobre cómputo final, declaración de validez del proceso electoral y declaratoria de presidente electo de la Sala Superior del Tribunal Electoral del Poder Judicial de la Federación de fecha 31 de agosto de 2012, misma que fue publicada en el Diario Oficial de la Federación, el 6 de septiembre de 2012. 
cho las elecciones deben ser democráticas acorde con los parámetros constitucionales y legales. Uno de los elementos fundamentales de un sistema democrático consiste en que las elecciones sean libres y auténticas. El artículo 41 de nuestra Constitución señala que "las elecciones deben de ser libres, auténticas y periódicas".

La base de la impugnación de la elección presidencial fue precisamente esa, pues se consideró en el juicio de inconformidad 359/2012, que las recientes elecciones no fueron libres ni auténticas. El juicio de inconformidad se sustentó en casos recientes del Tribunal Electoral del Poder Judicial de la Federación, en donde éste determinó o sostuvo la posibilidad de la invalidez de los proceso electoral por violaciones a la carta magna (SUP-JRC-604/2007, SUP-JRC-165/2008, ST-JRC-15/2008, ST-JRC-34 y 36/2008, ST-JRC-57/2011 y STJRC-117/2011). Es importante destacar que en el juicio de inconformidad la coalición Movimiento Progresista no acudió preponderantemente a las causales de nulidad de la ley secundaria sino que planteó la pretensión de invalidez con fundamento en los principios constitucionales. Se argumentó que si alguno de estos principios fundamentales es vulnerado, se actualiza la causal de invalidez de la elección. ${ }^{14}$

Los principales argumentos que se sostuvieron en el juicio de inconformidad para invalidar la elección presidencial son los siguientes: 1) profunda inequidad electoral por rebase de topes de gastos de campaña; 2) medios de comunicación electrónicos a favor de Enrique Peña Nieto; 3) empleo de tramas financieras paralelas para ocultar el origen de los recursos y evitar la fiscalización del IFE; 4) compra y coacción del voto, y 5) empleo de encuestas como propaganda electoral. $^{15}$

14 Ackerman, John, Autenticidad y nulidad. Por un derecho electoral al servicio de la democracia, México, UNAM, 2012, pp. 1-13.

15 En el juicio de inconformidad 359/2012, de las páginas 5 a 79 se narran los hechos. De las páginas 79 a 182 se realiza un estudio sobre la procedencia de la pretensión, fundamentalmente se expone que si se demuestra una violación a los principios constitucionales procede la invalidez de la elección. El primer agravio se argumenta de las páginas 182 a 225. En él se sostiene que durante el proceso electoral y previo al mismo hubo adquisición indebida de tiempos en radio y televisión para posicionar a Enrique Peña Nieto. En esta parte se detallan los vínculos entre la empresa Televisa y el candidato Enrique Peña Nieto (ejemplos: contabilidad creativa, “The Guardian”). El segundo agravio se refiere al excesivo gasto de campaña y rebase de topes (pp. 225-407). En él se desarrollan todas las quejas que la coalición Movimiento Progresista ha presentado ante la Unidad de Fiscalización del IFE para demostrar, con apoyo en la información que consta en esas 
Inequidad por rebase de topes de gasto de campaña. Rebasar el tope de campaña constituye una infracción expresa a la ley por parte de los candidatos, cuya sanción es la cancelación del registro de candidato. Constitucionalmente, rebasar topes de gasto de campaña, constituye una fuente de inequidad electoral que transgrede el principio de elecciones auténticas. En el juicio de inconformidad 359/2012, se sostuvo y se ofrecieron pruebas a ese respecto para acreditar que la coalición Compromiso por México erogó en la campaña presidencial la cantidad de $\$ 4599947834.00$. Esto es, un rebase escandaloso del tope permitido que confirmaba a juicio de la coalición Movimiento Progresista la inequidad del proceso y la procedencia de la invalidez por infracción al principio constitucional de elecciones auténticas.

Medios de comunicación electrónicos a favor de Peña Nieto. En el juicio de inconformidad 359/2012 se hicieron valer múltiples indicios que aluden a la existencia de un acuerdo comercial y político entre Peña y Televisa desde el año 2005. Estos indicios actualizan jurídicamente el supuesto constitucional que prohíbe la adquisición encubierta de tiempo en radio, televisión y demuestran además el carácter inequitativo de todo el proceso electoral. Las evidencias más sobresalientes que se aportaron como prueba en el juicio de inconformidad a este respecto fueron: los contratos con empresas de publicidad propiedad de Alejandro Quintero Íñiguez, vicepresidente de comercialización de Televisa; el reconocimiento de Carlos Loret de Mola, conductor de Televisa, del acuerdo entre Televisa-Peña; la cobertura de Televisa de las giras in-

denuncias, que se violentaron los topes autorizados por la autoridad electoral federal. El tercer agravio se ocupa de las aportaciones de personas prohibidas y de las estructuras de financiamiento paralelo (pp. 407-430). Es un estudio que alude al papel del Banco Monex y de las empresas que fondearon recursos a esa institución con el propósito de respaldar actos de campaña de Enrique Peña Nieto. El cuarto agravio abunda en el empleo de las encuestas como propaganda electoral y se trata en las páginas 430 a la 463 . El agravio sostiene que las encuestas constituyeron una adquisición indebida de tiempos en radio y televisión además de violentar la libertad del sufragio. El quinto agravio atiende el tema de la presión y coacción del voto (pp. 463-518). Se abunda en la parcialidad del uso de los recursos públicos por parte de servidores públicos del Partido Revolucionario Institucional y se detallan las denuncias y quejas que en la materia se han presentado ante el IFE que no han sido atendidas por la autoridad electoral federal y ante la FEPADE. De las páginas 518 a 637 se enlistan las pruebas presentadas. El segundo documento que acompañó al Juicio de Inconformidad es un alcance que estudia distintos temas, entre otros, la falta de certeza en los recuentos y cómputos realizados en los Consejos Distritales, así como la narración de incidentes vinculados a la presión y coacción del voto (consta de 40 páginas). Al final de este alcance, de las páginas 40 a 48 , se adicionan pruebas. 
ternacionales de Peña; facturas de Televisa por los conceptos de CoMENTARIOS DE JoAquín López Dóriga transmitidos DENTRO DE SU Noticiero "López DórigA" y EN EL NOTICIERo de OsCar Mario BeteTA, por $\$ 1,150,000.00$, y, finalmente, los gastos en publicidad y propaganda en medios de comunicación electrónicos que difundieron en 2010 las actividades gubernamentales de Peña por $\$ 87678347.84$.

Empleo de tramas financieras paralelas para ocultar el origen de los recursos y evitar la fiscalización del IFE. Se señaló en el juicio de inconformidad 359/2012 ante la Sala Superior del Tribunal Electoral del Poder Judicial de la Federación que diversas empresas "fantasma" y el Banco Monex realizaron transacciones para ocultar el origen de los recursos y violentar muchas disposiciones de la legislación electoral. Comercializadora Atama, Grupo Koleos, Grupo Tiguan, y Rodrigo Fernández Noriega aportaban recursos millonarios a Monex para que este banco contratara con otras empresas "fantasma" (Inizzio y Efra) la dispersión de tarjetas de prepago y de otra índole en beneficio de la estructura electoral del PRI y para comprar el voto. Se desconoce cuál es el origen de los recursos de las empresas mencionadas. Por la información que se dispone de ellas, éstas no tendrían los recursos para realizar operaciones económicas por más de doscientos millones de pesos. Los hechos son tan graves que las operaciones narradas podrían constituir, entre otros, el delito de lavado de dinero. Electoralmente las conductas anteriores implican: 1) aportaciones ilegales a la campaña de Peña Nieto de personas morales, lo que está prohibido por la ley electoral; 2) una estructura de financiamiento paralelo prohibida por la ley porque no se informa a la autoridad electoral sobre todas las fuentes de financiamiento; 3) rebase de topes de aportaciones privadas en la campaña del PRI-PVEM, y 4) rebase del tope de gastos de la campaña presidencial.

Compra y coacción del voto. El juicio de inconformidad señala que en varias partes del país, dirigentes y candidatos del PRI entregaron a los ciudadanos millones de tarjetas, principalmente de la tienda departamental Soriana. Estas tarjetas se entregaron a cambio de votos. De ello hay pruebas suficientes en el juicio de inconformidad, tanto en videos como en testimonios notariales.

Existen más de siete tipos distintos de tarjetas de Soriana: Soriana Mi Ahorro, Soriana Aprecio por ti, en el Estado de México y el Distrito Federal; Tamaulipas siempre gana PRI por Ti Soriana; Mercado 
Soriana Tarjeta Buen Vecino y Soriana Obsequia Aprecio de Nuevo León; Mi Ahorro Soriana, Chihuahua, y Soriana CTM.

Además, el juicio de inconformidad argumenta, que el PRI contrató alrededor de cinco millones de tarjetas telefónicas con la imagen de Enrique Peña Nieto. Estas tarjetas telefónicas prepagadas con tiempo aire de 100 pesos cada una, fueron distribuidas por todo el país, lo que implica un gasto, sin considerar el costo de las tarjetas, de 500 millones de pesos. Se ofreció como prueba un documento promocional de la empresa MarkCom, denominado "La Mejor Herramienta de Marketing Político, PRI Comprometidos con México, Tarjeta Telefónica Promocional".

Se indicó que los gobernadores del PRI utilizaron recursos públicos de los estados para comprar millones de votos en todo el país. Este aserto se probó, entre otros, con chequeras y otros documentos, que demuestran el empleo de los presupuestos estatales para comprar votos. Un caso paradigmático por las evidencias que fueron reunidas por la coalición "Movimiento Progresista" es el del Estado de Zacatecas.

La compra del voto fue más acentuada en el medio rural según el juicio de inconformidad. Por ejemplo, en los tres distritos con más población rural de Yucatán, se registró una participación promedio del $86 \%$. En Chiapas, la participación ciudadana, con respecto a 2006, se incrementó en $118 \%$ y el PRI-PVEM consiguió 506000 votos de más. En el medio urbano, con relación a 2006, la participación creció en 5.16\%, mientras en el medio rural aumentó en $23.37 \%$.

Encuestas como propaganda electoral. Empresas como GEA-ISA/ Milenio, El Universal/Buendía y Laredo, BGC/Excélsior, Consulta Mitofsky/Radio Fórmula/Televisa, entre otras, se dedicaron a difundir mediciones y pronósticos que no correspondieron a la realidad y cuyo propósito fue proyectar que la imagen de Enrique Peña Nieto era inalcanzable. Con esta manipulación se violaron los párrafos 2 y 3 del inciso $g$, de la base III, del artículo 41 de la Constitución, así como los artículos 49.3 y 49.4 del Código Federal de Instituciones y Procedimientos Electorales porque se actualiza la prohibición para adquirir tiempos en radio y televisión por particulares para fines electorales.

Desde la izquierda se insistió que la elección no fue ni libre ni auténtica. Se razonó que no fue libre porque el voto ciudadano se compró o coaccionó a cambio de dinero o de prebendas. El juicio de inconformidad 359/2012 indica que no fue auténtica porque las condiciones de la competencia no fueron parejas. El candidato Enrique Peña Nieto, 
del PRI y PVEM, tuvo a su disposición recursos por más de quince veces de los que dispusieron sus contendientes. El candidato Enrique Peña Nieto fue favorecido por los medios de comunicación electrónica a través del empleo de encuestas que tuvieron como fines la manipulación y confusión electoral y no la información a los ciudadanos. Además, se adujo que el candidato del PRI y del PVEM empleó tramas y triangulaciones financieras y bancarias como la del caso Monex para ocultar el origen de los recursos que utilizó en su campaña. El esquema de triangulación de recursos recurriendo a empresas fantasma constituye, según el escrito de juicio de inconformidad 359/2012, un marco de financiamiento paralelo prohibido por la legislación electoral.

\section{La resolución de la Sala Superior del Tribunal Electoral del Poder Judicial de la Federación. Descripción y crítica}

La resolución que dictó la Sala Superior del Tribunal Electoral para resolver el juicio de inconformidad 359/2012 es un ejemplo de obsecuencia con los poderes establecidos, tanto formales como informales o fácticos. Expongo cinco razones para sostener mi afirmación:

Diluyó su carácter de tribunal constitucional. El Tribunal Electoral del Poder Judicial de la Federación es un tribunal constitucional en materia electoral que puede desaplicar normas contrarias a la Constitución pero que sobre todo está diseñado para salvaguardar y garantizar que los principios jurídicos previstos en el texto de la carta fundamental se materialicen en el mundo fáctico. Es decir, como tribunal constitucional que es, está obligado a garantizar la Constitución normativa para que la realidad social coincida con la norma constitucional. Si los hechos no coinciden con la norma constitucional, el Tribunal Electoral debe señalarlo y reparar las infracciones constitucionales para que la realidad sociológica coincida con la Constitución. En el caso que nos ocupa el Tribunal Electoral se desvinculó de la Constitución normativa, al señalar que en las partes y no también en él, recae la carga de la prueba. A partir del criterio del Tribunal la defensa de la Constitución normativa es tarea exclusiva de los partidos y no del Tribunal. Desde la perspectiva del Tribunal su papel de garante de la Constitución es pasivo y no proactivo, es decir, poco garante o garante a medias de la Constitución. Le pide a las partes las pruebas 
para decir el derecho como cualquier tribunal de legalidad cuando por su carácter de tribunal constitucional su función primordial era hacer que la Constitución fuese una realidad, y para ello debía echar mano de todos los elementos a su alcance para esclarecer si hubo o no las violaciones a la Constitución que señalaba la coalición Movimiento Progresista.

No investigó. De acuerdo con la legislación secundaria electoral —artículos 6.3, 21 y 23 de la Ley General del Sistema de Medios de Impugnación en Materia Electoral- el Tribunal Electoral tiene facultades para requerir información, investigar, y suplir la deficiencia de los agravios. Estas facultades las empleó con gran reserva y sin maximizarlas. Por ejemplo, en los días previos a la decisión que declaró infundado el juicio de inconformidad, requirió información al IFE y a la FEPADE, la que citó pero no valoró en su resolución. En general, contuvo sus atribuciones de investigación y dejó que la Unidad de Fiscalización del IFE cargara con todo el peso de la investigación como si esta instancia administrativa fuese el auténtico tribunal constitucional en materia electoral. La Sala Superior del Tribunal Electoral se olvidó que como tribunal de plena jurisdicción podía realizar investigaciones adicionales, se limitó en sus atribuciones para dictar medidas para mejor proveer a fin de allegarse de elementos probatorios.

Se olvidó del contexto y por tanto no analizó las normas jurídicas desde el peso de los poderes fácticos. Dos ejemplos de la resolución prueban mi aserto. El primero tiene relación con la desestimación del argumento de compra y coacción del voto a través de la entrega de bienes utilitarios y de semovientes, pues el tribunal valoró que la entrega de estos bienes no acreditaban por sí mismos la compra del voto; con ello olvidó y no adminiculó la compra del voto con el incremento inusitado de la participación electoral en las casillas rurales, con el triunfo de Peña Nieto en esos ámbitos, con la despoblación y emigración de las zonas rurales hacia las ciudades y los Estados Unidos y, con los índices de pobreza alimentaria en esa zonas, obviando las necesidades de subsistencia de ese sector social y su relación con la propaganda clientelar contraria al voto libre y razonado. El segundo de los ejemplos tiene que ver con la desestimación del señalamiento de la coalición de izquierda sobre la publicidad encubierta a favor de Peña Nieto en relación con los informes de los relatores de la ONU y de la OEA en torno a la situación de la libertad de expresión y derecho a la información en México durante 2011; en ellos se constata que la 
concentración mediática del espectro radioeléctrico no promueve el pluralismo ni la democracia en México; el Tribunal no encontró los vínculos entre la fuerza e influencia de la televisión privada con la predilección de ésta por un candidato a la Presidencia de la República obviando el papel de los poderes fácticos como obstáculo en la construcción de una democracia pluralista.

Se resolvió sin tener sobre la mesa todos los elementos. La resolución en términos del artículo 17 de la Constitución no fue exhaustiva ni completa por la sencilla razón de que asuntos nodales que podrían haber incidido en el fondo del asunto se encuentran en proceso de investigación ante la Unidad de Fiscalización de los Recursos de los Partidos del IFE. ¿Cómo pudo el Tribunal Electoral validar una elección cuando no se sabe - porque las investigaciones están en cursosi existió lavado de dinero o peculado en los casos Monex o Soriana? ¿Puede ser legítimo un presidente que podría ser producto del lavado de dinero?

No se asume a plenitud el control de constitucionalidad ni el de convencionalidad. La resolución dice fundarse en la reciente reforma constitucional en materia de derechos humanos -interpretación conforme y pro homine - pero en ninguna parte de ella vemos maximizados los principios de elecciones libres y auténticas. No argumenta la resolución cómo realiza esos propósitos. En ninguna parte de ella se optimizan los derechos fundamentales de participación política. Jamás se maximiza el derecho a la información en relación con el voto libre e informado. Todo su contenido constituye una negación del derecho de acceso a la justicia. La resolución es un ejemplo de formalismo y de antigarantismo constitucional.

\section{Conclusiones. La reforma electoral que viene}

La reforma electoral 2007-2008 fue la más ambiciosa desde la de 1996. No obstante, quedaron pendientes de aprobación muchas asignaturas que otras reformas electorales y políticas tendrán que abordar ${ }^{16}$ y que

16 Como se sabe, una vez que se aprobó la reforma constitucional en materia electoral de 2007 se estimaba que serían aprobadas y reformadas 17 leyes secundarias. Sin embargo, sólo se modificaron seis: el Cofipe, la Ley Orgánica del Congreso; la Ley Orgánica del 
en el proceso electoral de 2012 pasaron factura a la calidad y constitucionalidad misma del proceso. Entre los temas que quedaron pendientes de aprobación y que pasaron factura en el proceso electoral de 2012 encontramos los siguientes:

1) La no aprobación de una nueva ley de radio, televisión y telecomunicaciones para desconcentrar el espacio radioeléctrico de la nación que hoy en día está concesionado en muy pocas manos (en un duopolio televisivo y en oligopolio en la radio).

2) La no derogación del financiamiento privado, lo que favorece legal e ilegalmente la participación del sector privado en los procesos electorales para esperar después beneficiarse de contratos, obras, concesiones y otros privilegios de los tres niveles de gobierno.

3) La no regulación de la publicidad gubernamental al no haberse expedido la reforma legal secundaria reglamentaria del artículo 134 de la Constitución, lo que propicia un gasto desmesurado, parcial y hasta corrupto en este rubro, además de inequidad en las contiendas electorales porque se busca con la publicidad gubernamental posicionar la imagen de los gobernantes en detrimento de otros futuros contendientes.

4) La no aprobación de la ley reglamentaria del artículo 6o. de la Constitución en materia de derecho de réplica, lo que constituyó en este proceso, un instrumento para homogeneizar el discurso público y reducir el derecho de información.

5) La no modificación de la Ley General del Sistema de Medios de Impugnación en Materia Electoral para ampliar las causales de nulidad electoral e incorporar entre sus supuestos el rebase de topes de gastos de campaña - todo ello en contra de la equidad electoral一.

6) La no revisión del estatus jurídico de la Fiscalía para la Atención de Delitos Electorales a fin de dotarla de mayores atribuciones y de autonomía frente al Ejecutivo Federal para no producir impunidad en materia electoral.

7) La no revisión del catálogo de delitos electorales previstos en el título XXIV del Código Penal Federal, lo que estimula la comi-

Poder Judicial Federal; la Ley General del Sistema de Medios de Impugnación en Materia Electoral; el Código Fiscal de la Federación, y la Ley de Instituciones de Crédito. 
sión de conductas delictivas en perjuicio de los principios y procedimientos democráticos.

8) La no determinación de responsabilidades políticas, administrativas y penales al titular del Poder Ejecutivo Federal por violación a normas electorales, lo que incide indebidamente en los procesos electorales.

9) La no sustitución de los spots por debates entre candidatos, lo que dificulta las posibilidades del voto libre e informado.

10) La superficialidad con la que se reguló la fiscalización a partidos y agrupaciones políticas, pues no se previó, entre otras cosas, la fiscalización concomitante de carácter permanente y la obligación a cargo del IFE para que las quejas que en materia de fiscalización se promovieran durante el proceso electoral se resolvieran antes de que éste se califique o valide.

11) La pobre regulación en materia de encuestas para impedir que éstas se usen como propaganda electoral en violación a diversas normas constitucionales y legales de carácter electoral en materia de contratación y adquisición de tiempos en radio y televisión.

12) El olvido de la participación ciudadana - aunque no sólo en este ámbito- en los medios de impugnación en materia electoral para conferirles legitimación procesal activa a los ciudadanos para interponer medios de impugnación en materia electoral, lo que partidocratiza aún más el proceso electoral.

13) La débil y vaga obligatoriedad de colaboración de las autoridades federales, estatales y municipales con la autoridad electoral durante los procesos electorales, lo que inhibe que ésta cumpla adecuadamente sus fines y, propicia que el IFE y el Tribunal Electoral del Poder Judicial de la Federación no desplieguen con amplitud sus competencias.

14) La insuficiente regulación en materia de compra y coacción del voto, lo que impide la efectividad del voto universal, libre, secreto y directo, sin presión y sin coacción.

15) La no modificación del mecanismo de elección de consejeros y magistrados electorales, lo que favorece que éstos sigan siendo correas de transmisión de la voluntad de las dirigencias de los partidos políticos mayoritarios en el seno de los órganos electorales. 